\title{
Congenital Anomaly of Pulmonary Veins
}

National Cancer Institute

\section{Source}

National Cancer Institute. Congenital Anomaly of Pulmonary Veins. NCI Thesaurus. Code C110942.

Aberrant drainage of one or more of the pulmonary veins which causes the return of oxygen-rich blood to the right atrium. 